\title{
Research on the Construction of the Internet Plus Regional Logistics Model
}

\author{
Qin XU
}

Wuhan Business University, Wuhan, 430056, China

E-mail:863097625@qq.com

Key words: Internet Plus; Regional Logistics; Model Construction

\begin{abstract}
Along with the rapid development of social economy, the increasingly advanced science and diversified and personalized consumer demand greatly promote the development of logistics as the third interest source. The newly-emerging model of Internet Plus drives many industries into internet development model. Logistics is undoubtedly one of them since it focuses on materials and transcends time and space completely in line with internet, which accordingly leads to a good growth momentum of the Internet Plus Logistics Model. Thus, this paper is intended to put forward a new logistics model complying with the background of Internet Plus Initiative and making up for the shortage of traditional regional logistics and theoretically support the draft of regional logistics policy and the construction of infrastructure. Besides, the new model can also attract more investment and raise revenues.
\end{abstract}

\section{Introduction}

Along with the rapid economy development and increasingly advanced science and technology, the modern logistics industry has not only become an essential part of the modern economy, but also developed into a more economical and reasonable integrated service model during the industrialization process. [1] Thus, it is now the basic industry of national and regional socio-economic development and even significantly symbolizes the level of national and regional economy, which accordingly makes itself the accelerator of regional economy. Generally, Chinese logistics industry is rapidly developing in line with the development of market economy in recent years. To optimize the economic structure, improve the investment environment and enhance regional economic competitiveness, many provinces have strategically planned or are planning their logistics system. And logistics demand as an important part in the system provides the basis for the draft of regional logistics policy, the scale of infrastructure construction and the analysis of logistics market trends. Chinese logistics industry is still in a preliminary phase of development, which means the statistic analysis of traditional logistics is limited. However, the newly-raised Internet Plus Initiative completely changes and greatly improves development models of many industries including logistics industry. [2]Logistics, relying on its role of the third interest source and its similarity to internet, leads to its combination with internet, namely Internet Plus Logistics. Under the background of rapid economic development and limited statistics analysis, how to reasonably predict the regional logistics demand becomes more and more important.

\section{Current Study on Regional Logistics Demand}

\section{A. Definition of Regional Logistics}

According to professor He Ping, regional logistics demand means the demand of space, time and efficiency on which social economic activities rely to distribute and utilize materials from production, circulation and consumption in the required time and in a fully-developed region. That means, this demand covers all logistics stages as well as relative information. Professor Mei Quanning holds the idea that it equals to the quantity of consumed logistics services through market exchange. It not only reflects the capacity of regional logistics market, but also the development trends of the whole economic industrial structure. [3]Professor Zhang Yan and her partners insist 
that it includes the quantity demanded and pattern of demand. The quantity means the total number of demand from all logistics stages while the pattern is evaluated by time, fee efficiency and many other factors. Qin Lu divides this demand into three parts, i.e. agricultural products, industrial products and consumer goods.

\section{B. Influence Factors of Regional Logistics}

Professor Huang Hu holds that the main influence factors of regional logistics are economic factors, factors inside logistics industry, environmental factors and so on which mainly cover level and scale of regional economic development, economic-industrial structure, economic spatial allocation, logistics facilities and services, changes in logistics fee and so on. Yang Guanghua has specifically studied the influence of industrial structure on logistics in Hunan Province and found out that the annual growth rate of logistics industry there reached up to $15 \%$ 20\% which is in line with the shift of the ratio among the primary, secondly and tertiary industry from 42.3:40.2:17.5 in 1980 to $14.7: 46.0: 39.3$ in 2010.

\section{Literature Review of Internet Plus Logistics}

According to Xia Jingming, the point-axis-net pattern of logistics system is essentially consistent with the entrance-link-platform pattern of internet system. [4]The net model combining with big data and cloud computing will finally develops into ecosystem model. Thus, the logistics model in the future will develop rapidly motivated by platform, internet, big data and ecosystem. The research center in HeadSCM states that Chinese top ten platform models in 2014 mainly include platform of logistics park, road, LTL special line, transport capacity resources, finance lease, taxi taking and so on. It is characterized by the integration of logistics resources through internet, the information integrated management and the running of Internet Plus Logistics Initiative. Cai Jin insists that this initiative calls for technological progress, efficiency improvement and organizational innovation or transformation. [5]That means, we should reflect the essence of logistics, improve organizational model, upgrade functional model, optimize commercial model and innovate development model by transforming target model and enhancing logistics running model.

\section{Influence of Internet Plus Initiative on Regional Logistics Development}

\section{A. Sharing regional logistics resources}

Taking full advantage of platformization, big data and other resources from internet, regional logistics is able to share logistics resources in intelligent match and operation monitoring and finally contribute to the sound running of the whole logistics ecosystem. Besides, the Internet Plus Initiative also provide logistics firms with broader platform which means more convenient financing, enhanced competitiveness as shown in Table 1. What's more, the combination between internet and regional logistics greatly raises the possibility of logistics industry integration. In other words, the large scale of investment can promote the common development of regional logistics and allow regional logistics subsystems to thrive. 
Table 1: Financing amount of some O2O firms in 2016

\begin{tabular}{|c|c|c|}
\hline Time & Firm & Financing Amount \\
\hline Jan. 2016 & Quanfeng Express & 2.2 billion yuan \\
\hline Jan. 2016 & Huolala Express & 12 million dollars \\
\hline Feb. 2016 & Logistics Secretary Express & 12 million dollars \\
\hline Feb. 2016 & Bird Taotao Express & 6 million dollars \\
\hline Mar. 2016 & Logitech Express & 1.35 billion dollars \\
\hline Mar. 2016 & Waytung Global Group Lmited & 30 million dollars \\
\hline Apr. 2016 & Yunce Express & 12 million dollars \\
\hline Apr. 2016 & ZTO Express & 12 billion yuan \\
\hline May. 2016 & Go Go Van & 12 million dollars \\
\hline May. 2016 & Dada Express & 1.2 billion yuan \\
\hline
\end{tabular}

\section{B. Personalizing Regional Logistics Information}

Because of the increasingly fierce competition, regional logistics attaches more and more importance to its services. Information personalization which focuses on user experience has accordingly become hot spot in kinds of areas of internet. Thus, it is urgent for logistics industry to take comprehensive reform, push information correctly and improve efficiency of users and industry. It can attract logistics firms and owners by some operation methods and strategies. Besides, it can increase the communication between logistics suppliers and buyers, monitor transport, warehousing and distribution finally promote the common development of regional logistics.

\section{Realizing Regional Logistics Information Management}

Regional logistics collaboration makes every part of social production and daily life there into integrity. Each link of logistics business constitutes a part of logistics system. And the informatization of single part is the basis of that of the whole system. Since information can only transfer to productivity after information selection and digestion, information management is very important. [6] It not only means automatic and mechanized operation, but also means collection and handling of information during the commercial and logistics process, analysis of those information and utmost instruct and manage regional logistics activities by full use of useful information.

\section{Innovative Construction of the Internet Plus Regional Logistics Model}

According to our previous research on regional logistics, we find out that the regional logistics system is a specially-structured, complicated, open and integrated system inside which the logistics system intertwine and interact with its environment. The main subsystems include logistics function system, logistics network system and logistics demand system as shown in Figure 1. 


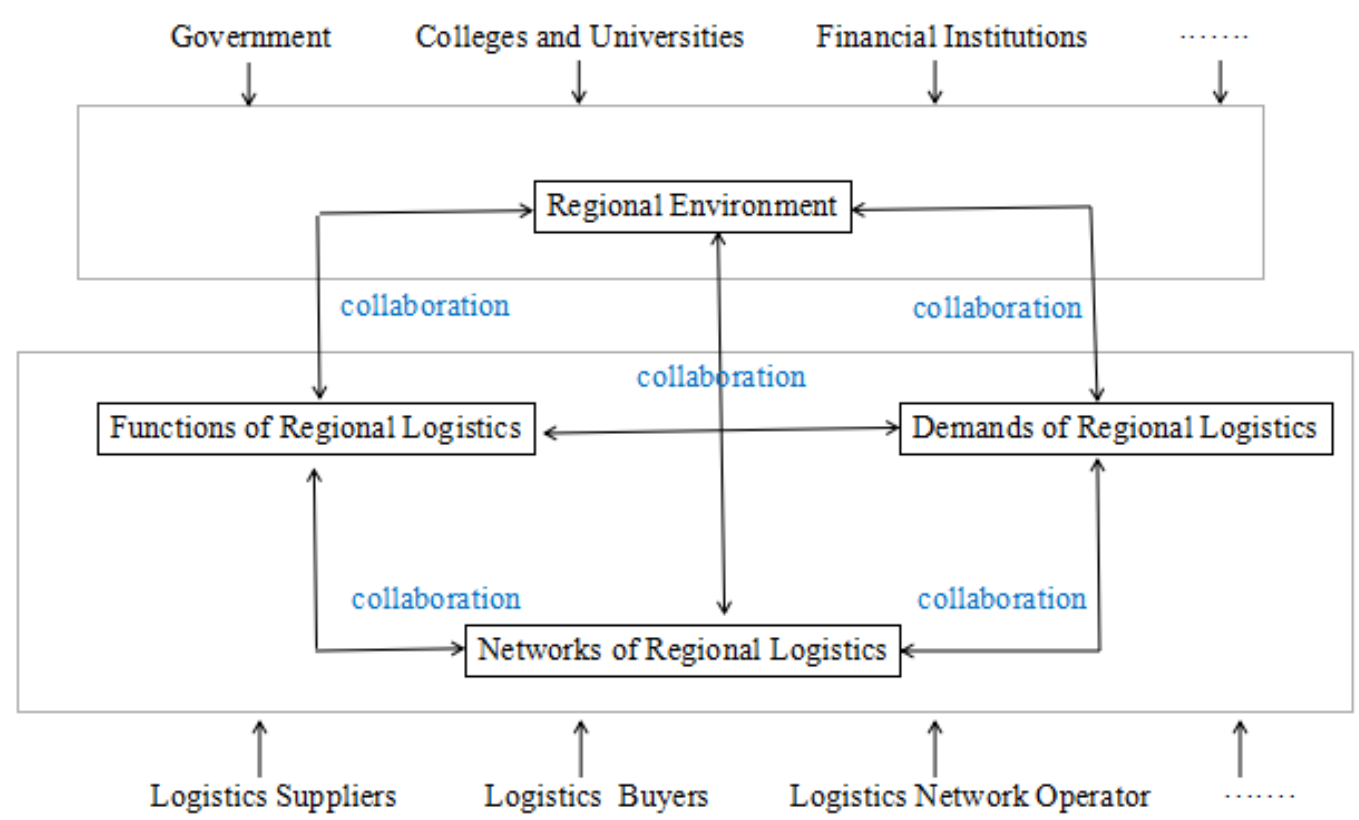

Figure 1: Innovative construction of regional logistics model

Firstly, the intelligent technology, advanced sensors and sensor networks realize the real-time online communication. And the internet-based call center and dispatching system provide platform of information release and information of cargo distribution and transportation navigation. These all change and improve the traditional logistics model and contribute to the appearance of innovative value-creating model.

Secondly, big data of logistics newly becomes infrastructure resources and value point of the whole logistics industry. It successfully increases firms' core resources and enhances their core competence.

Thirdly, free internet-based business model, confusing the public about the key business and the sources of cost and profit, is a characteristic in the internet era. Actually, big data, efficient marketing, optimized lead inventory and logistics resources not only reduce cost and risks largely, but also increase volume and revenue greatly. And the back-end data and extending marketing make the logistics industry possible to be free, which completely reverses the traditional logistics business model.

Fourthly, EDI, focusing on the delivery of information about orders, invoices, logistics and so on among companies, can remove most obstacles in online business and smooth most online business.

These all above, including planning, layout, logistics management, market structure and even business model, profoundly contribute a lot to the construction of innovative regional logistics model.

\section{Conclusion}

Along with the Internet Plus Initiative, regional logistics construction is taking its new round of upgrade and reform. This paper studies the Internet Plus Regional Logistics model, which realizes the integration of logistics factors distribution, logistics resources and logistics system based on some relative theories and promotes the establishment of integrated linkage mechanism by informatization, and puts forward some corresponding suggestions. The author hopes that this paper will to some degree provide perfect theoretical basis for the draft of regional logistics development policy and the scale determination of regional logistics infrastructure. 


\section{Acknowledgement}

In this paper, the research was sponsored by Strategies on the Construction of Public Logistics Information Service Platform (PLISP) in Wuhan (Project No. 2014A006).

\section{References}

[1] Kajal Lahiri,Vincent Wenxiong Yao.Economic indicators for the US transportation sector. Transportation Research Part A:Policy and Practice . 2006

[2] Wei-Bin Zhang.Economic geography and transportation conditions with endogenous time distribution amongst work,travel,and leisure. Journal of Transport Geography. 2007

[3] Keith G.Debbage.Air transportation and urban-economic restructuring:competitive advantage in the US Carolinas. Journal of Air Transport Management . 1999

[4] Carig R Carter,Marianne M. Jennings.Social responsibility and supply chain relationships. Transportation Research Part . 2002

[5] Joseph R Carter,John N Pearson, etal.Logistics Barriers to International Operations:The case of the People’’s Republic OF Chain. Journal of Business . 1999

[6] Garrido R A,Mahmassani H S."Forecasting Freight Transportation Demand with the Space-Time Multinomial Probit Model”. “Transportation Research B” . 2000 